\title{
Microwave assisted accelerated fluoride adsorption by porous nanohydroxyapatite
}

\author{
A.K.D. Veromee K. Wimalasiri ${ }^{\text {a }}$, M. Shanika Fernando ${ }^{\text {a }}$, Gareth R Williams ${ }^{\text {b }}$, Dhammike P. Dissanayake \\ ${ }^{a}$, K. M. Nalin de Silva ${ }^{a}$, Rohini M. de Silva ${ }^{\text {a* }}$ \\ ${ }^{a}$ Centre for Advanced Materials and Devices (CAMD), Department of Chemistry, University of Colombo, \\ Colombo 00300, Sri Lanka. \\ ${ }^{\mathrm{b}}$ UCL School of Pharmacy, University College London, 29-39 Brunswick Square, London, WC1N 1AX, \\ UK \\ *Corresponding author: \\ rohini@chem.cmb.ac.lk
}

\begin{abstract}
Fluoride pollution of water is a matter of concern in many countries due to its association with chronic kidney failure. Therefore, it is important to develop fast and efficient methods for fluoride removal from drinking water using environmentally friendly materials. In this article, the synthesis, characterization and microwave assisted accelerated fluoride removal by porous nanohydroxyapatite (PHAP) are reported. The PHAP samples were synthesized using polyvinyl pyrrolidone and sodium dodecyl sulphate micellar system as the template. The prepared nanohydroxyapatite was characterized using TEM, SEM, FT-IR, TGA, XRD and BET. Investigation of the morphology of microcrystals using TEM showed the presence of spherical particles of 20-35 nm size and highly porous rod-shaped crystals with the aspect ratio of 2:13. The adsorption of $\mathrm{F}^{-}$ions using PHAP was carried out under the influence of microwave radiations using concentrations comparable to existing $\mathrm{F}^{-}$levels in natural water. The equilibrium is reached within $80 \mathrm{~s}$ and this is the fastest saturation recorded for any existing material. Kinetic experiments showed that the fluoride adsorption is an activated second order process. The equilibrium fluoride adsorption capacity of PHAP was found to be $9.19 \mathrm{mg} / \mathrm{g}$ at $\mathrm{pH} 6.5$ for $80 \mathrm{~s}$ and this was proven to be a potential material to remove $\mathrm{F}^{-}$ions rapidly from drinking water.
\end{abstract}

Key Words: Microwave, porous nanohydroxyapatite, template, fluoride, adsorption isotherm 


\section{Introduction}

Fluoride is considered as an essential mineral with a narrow margin of safety for human wellbeing.[1] According to the WHO guidelines, the recommended fluoride concentration in drinking water is in the range of $0.5-1.5 \mathrm{mgL}^{-1}$.[2] The prolonged use of drinking water containing even a relatively low dose of fluoride have adverse effects on human health and shows dental caries even with very low concentrations such as $0.5 \mathrm{mg} \mathrm{L}^{-1}$ and greater than $10 \mathrm{mg} \mathrm{L}^{-1}$ can lead even to crippling fluorosis.[3] For example, over 90\% of children in dry zone of Sri Lanka show dental fluorosis where the fluoride content in water is even less than $1 \mathrm{mg} \mathrm{L}^{-1}$.[10] In addition, there are many reports indicating various other diseases caused by high fluoride intake such as osteoporosis,[4],[5] arthritis,[4],[6] brittle bones,[4],[5],[6] infertility,[4] brain damage,[4] alzheimer syndrome[7] thyroid disorder, and chronic kidney disease of unknown aetiology (CKDu).[4]' [8] It has also been reported that the fluoride levels over $2.0 \mathrm{mg} \mathrm{L}^{-1}$ cause increased activities of serum lactic dehydrogenase (LDH), urine $\mathrm{N}$-acetyl- $\beta$-glucosaminidase (NAG), and urine $\gamma$-glutamyl transpeptidase $(\gamma-\mathrm{GT})$ in children and damage liver and kidney functions.[9]

Thus, the ingestion of elevated fluoride concentrations via drinking water is a matter of concern. Both natural and anthropogenic activities contribute to increase the fluoride content in drinking water. Many fluoride containing minerals and rocks such as fluorite, topaz, biotite, cryolite, granite, shale, basalt and syenite are widely distributed in the earth's crust.[11] Although these rocks and minerals are hardly soluble in water at neutral $\mathrm{pH}$, when the conditions are changed, fluorides can be leached to the ground water.[11], [10] In addition, various industrial effluents containing high fluoride concentrations and also contribute to increased levels of fluoride in water.[12]

Therefore, the removal of excess fluoride from drinking water systems has received much attention and various treatment techniques such as chemical precipitation,[13] adsorption,[14],[15] reverse osmosis,[16],[17],[18] nanofiltration,[19] and electrodialysis[20],[21] have been employed for water defluorination. Among these methods, adsorption is a promising technology due to its simplicity of design, operation and cost effectiveness. Activated alumina,[22],[23]' calcium based materials,[24],[25],[26] ironbased sorbent materials,[27],[28] metal oxides/hydroxides/oxyhydroxides/ metal-impregnated oxides,[29],[30] carbon based materials,[29],[31] layered double hydroxides,[32],[33],[34] and hydroxyapatite,[35],[36] have been considered as attractive sorbents in defluorination. Among the variety of materials used for defluorination, hydroxyapatite (HAP) has been identified as one of the promising 
materials for the removal of fluoride from water mainly due to cost-effectiveness and biocompatibility. Moreover, the application of variety of morphologically different HAP in water defluorination, such as nano HAP, [37] [38] [39] porous HAP, [40,41]' nanowires, [42], nanorods of HAP [43],[38] and also hollow nano HAP [44],[45] has been reported. The facile synthesis of hydroxyapatite with complex and fascinating morphologies requires mimicking of the natural biomineralization process.[46] Therefore, the organic templates with complex functional patterns were used to control the nucleation, growth and alignment of inorganic crystals.[47,48]

The objective of our study was to investigate the effect of microwave energy on fluoride adsorption onto porous nano HAP as it has never been considered for HAP systems. In addition, the possibility of removing $\mathrm{F}^{-}$ions at concentrations existing in natural water at natural $\mathrm{pH}$ conditions were investigated as almost all the existing literature work has dealt with very high concentrations of $\mathrm{F}^{-} \mathrm{using}$ low $\mathrm{pH}$ conditions. For this purpose, the hollow microspheres /nanospheres of hydroxyapatite and highly porous nanorod assembled crystals of hydroxyapatite were synthesized using polyvinyl pyrrolidone and sodium dodecyl sulphate (PVP/SDS) template assisted system. The synthesized material was tested for fluoride removal from aqueous solutions and was found that the adsorption process can be significantly enhanced by increasing the kinetic energy using microwave.

\section{Experimental}

\subsection{Materials}

All the chemicals used in this study were of analytical grade and they were used without any further purification. Polyvinylpyrrolidone (PVP) average molecular weight 10,000 and sodium dodecyl sulfonate (SDS, 98\%) were purchased from Sigma-Aldrich Ltd. Calcium nitrate tetrahydrate (98\%) from Techno Pharmchem, India was used in the synthesis along with ammonium monohydrogen phosphate (99\%, Sigma Aldrich). Sodium fluoride (99.5\% Merck) was used to prepare fluoride stock solution.

\subsection{Synthesis of porous nanohydroxyapatite (PHAP)}

Porous nanohydroxyapatite was synthesized by the wet chemical precipitation method. Briefly, the template for the synthesis was prepared by adding $25 \mathrm{ml}$ of $20 \mathrm{~g} / \mathrm{L}$ PVP and $25 \mathrm{ml}$ of $60 \mathrm{mM}$ SDS into a three neck flask. The mixture was heated up to $60{ }^{\circ} \mathrm{C}$ and stirred for $1 \mathrm{~h}$. To this solution, $0.4 \mathrm{M} \mathrm{Ca}\left(\mathrm{NO}_{3}\right)_{2} \cdot 4 \mathrm{H}_{2} \mathrm{O}$ and 
$0.15 \mathrm{M}\left(\mathrm{NH}_{4}\right)_{2} \mathrm{HPO}_{4}$ in $1.67 \mathrm{Ca} / \mathrm{P}$ molar ratio were added drop wise while stirring. During the process, $\mathrm{pH}$ of the medium was maintained at 10 using $3.5 \mathrm{M} \mathrm{NH}_{4} \mathrm{OH}$ solution. The reaction mixture was maintained at $80{ }^{\circ} \mathrm{C}$ for $3 \mathrm{~h}$ under vigorous stirring. The mixture was aged for $24 \mathrm{~h}$, then it was centrifuged and washed several times using distilled water and dried.

\subsection{Characterization of the samples}

Morphological and structural studies of synthesized PHAP samples were conducted using Scanning Electron Microscopy (HITACHI SU6600, at $15.0 \mathrm{kV}$ ). The transmission electron microscopic analysis (TEM) was carried out using JEOL JEM 2100 electron microscope. The presence of functional groups of nanohydroxyapatite was confirmed by studying the sample using a FT-IR spectrometer (Varian 660-IR) in the wavenumber range of $500-4000 \mathrm{~cm}^{-1}$. The X-ray powder diffraction patterns of the samples were obtained using a Bruker D8 Focus X-Ray-Diffractometer using $\mathrm{Cu}$ K $\alpha$ radiation ( $0.154 \mathrm{~nm}$ ) over the $2 \Theta$ range of $2^{\circ}-80^{\circ}$, with a step size of $0.02^{\circ}$. The thermal gravimetric analysis for the respective samples was carried out using a thermogravimetric analyzer (TGA SDT Q 400) in the temperature range from room temperature to $600{ }^{\circ} \mathrm{C}$. The surface area of synthesized PHAP was measured by BECKMAN COULTER SA3100 BET analyzer.

\subsection{Adsorption study}

The stock solution of fluoride was prepared by dissolving $5.0 \mathrm{~g}$ of sodium fluoride in $1 \mathrm{~L}$ distilled water in a PVC container. The experimental solutions for adsorption and analysis were freshly prepared by diluting $\mathrm{F}^{-}$stock solution with distilled water. All the experiments were conducted using vessels made of polypropylene or PVC. The total ionic strength adjusting buffer (TISAB-III) solution was added to all the samples (1:1) before measuring the fluoride concentrations using a fluoride selective electrode (Orion ion selective electrode).

\subsubsection{Influence of $\mathrm{pH}$ on the fluoride uptake capacity}

The influence of the $\mathrm{pH}$ on fluoride uptake capacity was investigated by controlling the $\mathrm{pH}$ level of the system from 1 to 13 using $0.1 \mathrm{M} \mathrm{HCl}$ and $0.1 \mathrm{M} \mathrm{NaOH}$. The solution $\mathrm{pH}$ and concentration of fluoride were determined using a pH electrode and a fluoride ion selective electrode, respectively.

\subsubsection{Adsorption kinetic study}

The adsorption kinetic studies were carried out using two different methods (Method 1 and Method 2). 
Method 1

Adsorption of fluoride by porous nanohydroxyapatite was continuously monitored using fluoride ion selective electrode at three different temperatures. Adsorption of fluoride by $0.04 \mathrm{~g}$ of porous nanohydroxyapatite from a $5 \mathrm{ppm}$ solution $(20 \mathrm{ml})$ was studied at 30,50 and $80{ }^{\circ} \mathrm{C}$ for $2 \mathrm{~h}$ with continuous stirring at $180 \mathrm{rpm}$.

Method 2

Polypropylene vials containing $20 \mathrm{ml}$ of $5 \mathrm{ppm}$ fluoride solution and $0.04 \mathrm{~g}$ of porous nanohydroxyapatite was exposed to microwave radiation (180 $\mathrm{W}$ of SAMSUNG TDS microwave, $230 \mathrm{~V}$ ) for a predetermined time (from 5 to $120 \mathrm{~s}$ ). The residual fluoride levels were measured using the fluoride ion selective electrode.

\subsubsection{Adsorption isotherms}

In the adsorption isothermal studies, $0.02 \mathrm{~g}$ of porous nanohydroxyapatite was added to $10 \mathrm{ml}$ of fluoride solution at the concentrations ranging from 1 to $20 \mathrm{ppm}(1,3,5,10,15$ and $20 \mathrm{ppm})$ and the solution $\mathrm{pH}$ was adjusted to 6.8. After exposing it to microwave energy for $80 \mathrm{~s}$, the residual fluoride concentration was measured using the fluoride ion selective electrode. In addition, the adsorption studies were carried out with higher concentrations of $\mathrm{F}^{-}$(150 and $200 \mathrm{ppm}$ ) (Figure S2) in order to compare adsorption capacities obtained at higher concentrations in reported works.

\section{Results and discussion}

\subsection{Characterization of PHAP}

In the aqueous system, SDS molecules start to form micelles at critical micelle concentration (CMC) by arranging their head groups toward the surrounding medium while directing the hydrophobic tail regions

in the micelle center. CMC of SDS surfactant is $8.3 \mathrm{mM}$ at $25{ }^{\circ} \mathrm{C}$ and it increases with increasing temperature $[49,50]$. In this study, $60 \mathrm{mM}$ concentration of SDS was used and the reaction medium was heated up to $60{ }^{\circ} \mathrm{C}$. It is reported that the CMC value of SDS at $60{ }^{\circ} \mathrm{C}$ is $9.2 \mathrm{mM}[49,51]$. The used concentration of SDS is $60 \mathrm{mM}$ and it is about 6 times greater than the $\mathrm{CMC}$ value of SDS at $60{ }^{\circ} \mathrm{C}$. It is very important to maintain the system with high SDS concentration in order to obtain higher amounts of micelles[52] to increase the porous nature of HAP. As described earlier, during the nucleation process, 
these micelles act as templates as well as nucleation sites for HAP crystallization. Higher the number of micelles trapped inside HAP, higher would be the porosity of HAP.

The driving force for the micelle formation is the minimization of contact between water and hydrophobic tail region. The thermodynamic feasibility of the micelle formation can be expressed as follows [49],

$$
\Delta G^{\circ}=-R T \ln (C M C)
$$

The free energy change for the micelle formation at $60{ }^{\circ} \mathrm{C}$ is approximately $-13 \mathrm{~kJ} \mathrm{~mol}^{-1}$.

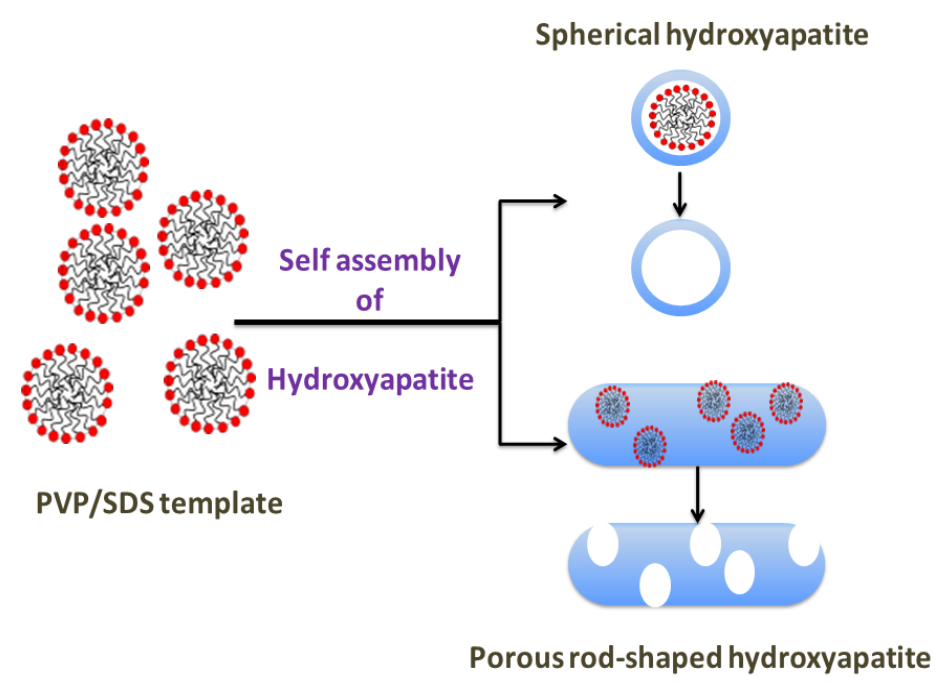

Figure 1: Self - assembly of hydroxyapatite

PVP molecules can strongly interact with anionic SDS head group to form PVP-SDS spherical shaped complex micelles [53,54] (Figure 1). Furthermore, the calcium ions in the medium also have very high affinity towards these anionic head groups and, therefore, these SDS molecules in the PVP-SDS complex micelles provide nucleation sites for the crystallization of hydroxyapatite.

The scanning electron micrograph (SEM) of nanohydroxyapatite synthesized in the presence of the polymer-surfactant template (PVP/SDS) is shown in Figure 2. According to the image, there are rod shaped and spherical shaped particles and they are combined or agglomerated in such a way to provide many pores/groves to give a complex hollow nature. In addition, the sample surface is uneven providing a high surface area with nanogrooves of the size ranging over $80-200 \mathrm{~nm}$. This is in contrast with the morphology of rod shaped hydroxyapatite nanoparticles synthesized using 
the same conditions in the absence of the PVP/SDS template [38]. Therefore, it is very clear about the template effect of PVP/SDS to provide hollow morphology of nanohydroxyapatite.

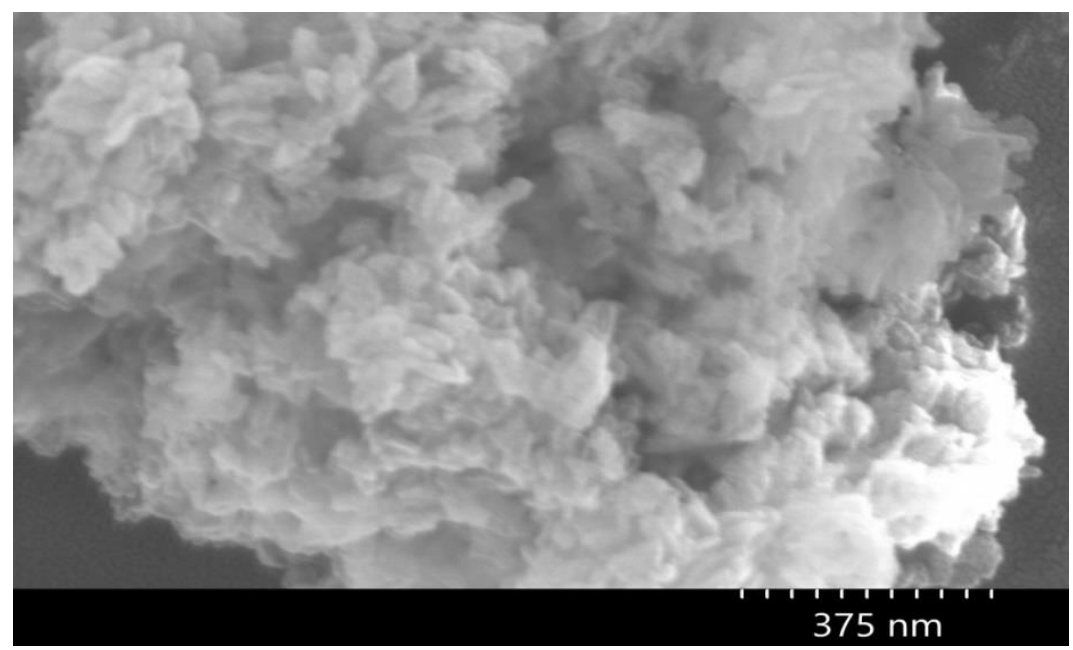

Figure 2: SEM image of porous hydroxyapatite (PHAP)

The porous nature of synthesized HAP was further confirmed using transmission electron microscopy (TEM), as shown in Figure 3. The formation of both spherical and rod shape nanoparticles can be

observed in these micrographs (Figure 3 (a) and (b)). A careful observation of the Figure 3(c) shows the existence of a spongy nature having tiny holes connected and spread along each particle giving a porous structure. Moreover, the size range of the spherical shaped hydroxyapatite is approximately $20-35 \mathrm{~nm}$ in

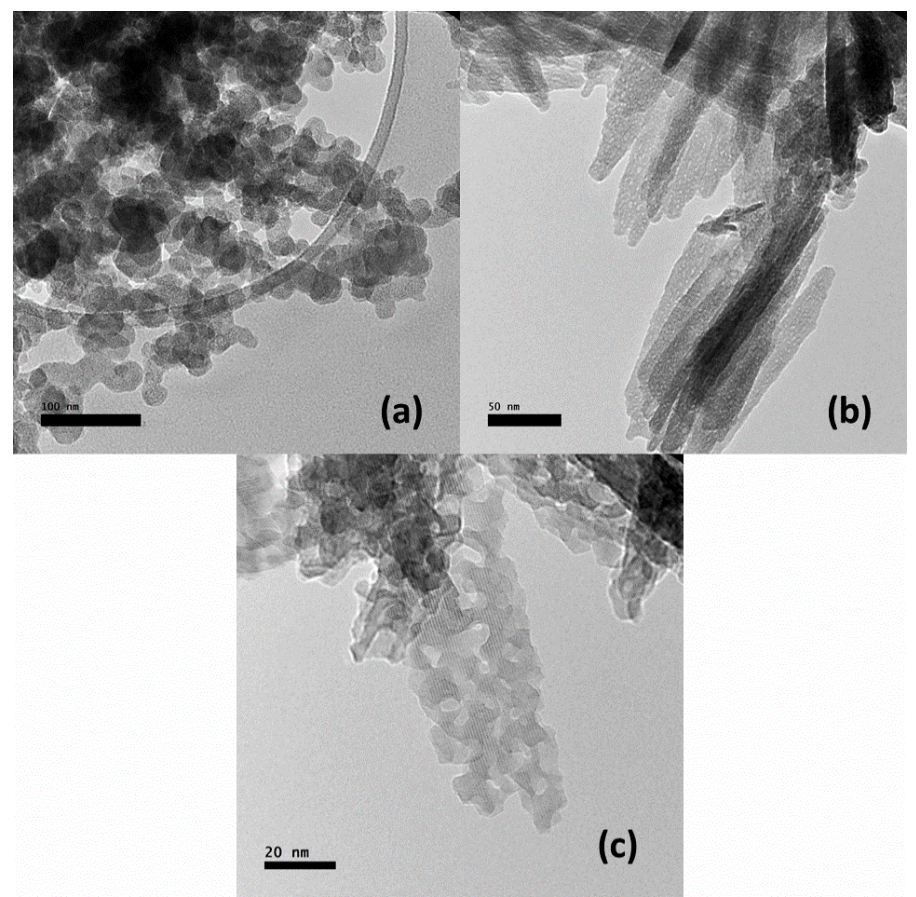

diameter and the aspect ratio of rod shaped nanoparticles is $2: 13$.

Figure 3: TEM images of porous microspheres/rods of hydroxyapatite. (a) Spherical shaped hydroxyapatite, (b) and (c) porous rod-shaped hydroxyapatite at different magnifications 
The FTIR spectra of unwashed and washed PHAP samples are shown in Figure 4. The IR adsorption bands at $3464 \mathrm{~cm}^{-1}$ and $1652 \mathrm{~cm}^{-1}$ can be attributed to the bending vibration mode of $\mathrm{H}$ bonded $\mathrm{OH}$ groups present in hydroxyapatite. The peak at $1020 \mathrm{~cm}^{-1}$ corresponds to the stretching mode of $\mathrm{PO}_{4}{ }^{3-}$ groups and the peaks at 601 and $850 \mathrm{~cm}^{-1}$ are the bending modes of $\mathrm{PO}_{4}{ }^{3-}$ groups $[38,55,56]$. The assignment of vibrational frequencies observed in the IR spectra is given in Table S1. The IR band appeared in the region of 1350$900 \mathrm{~cm}^{-1}$ is a combination of several overlapping peaks such as $\mathrm{CH}_{2}$ wagging, $\mathrm{SO}_{2}$ asymmetric stretching and the vibrational modes associated with phosphate groups and CN bond vibrations of PVP. The FT-IR spectrum of the washed PHAP does not show the IR absorptions related to PVP/SDS. The absence of IR bands correspondent to both PVP and SDS in washed PHAP (Figure 4) confirmed their absence on the surface. However, template of PVP/SDS present deep inside the PHAP particle may have not being removed during the washing process as indicted in the TGA analysis given in Figure 5.

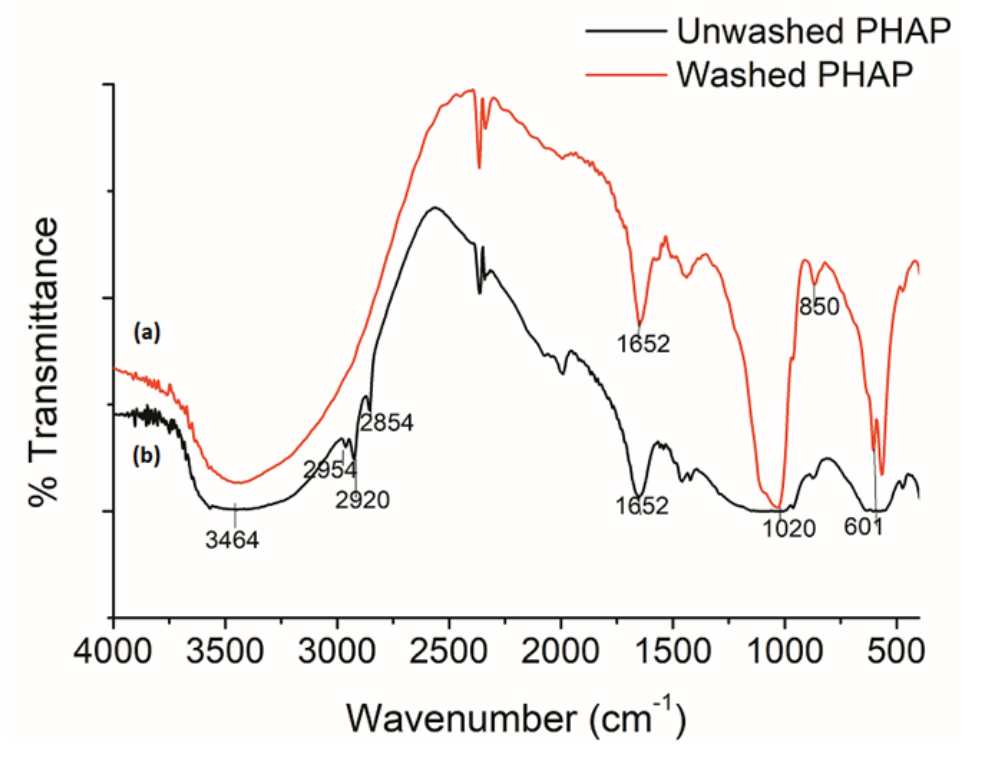

Figure 4: FT-IR spectra of (a) washed PHAP and (b) unwashed PHAP

In this study, TGA was accomplished under nitrogen and oxygen environments separately. Weight loss corresponding to PVP and SDS [57-59] were identified as $2.54 \%$ at the temperature range of $220-400{ }^{\circ} \mathrm{C}$ and $3 \%$ at the temperature range of $215-540{ }^{\circ} \mathrm{C}$ for nitrogen and oxygen environments respectively. 

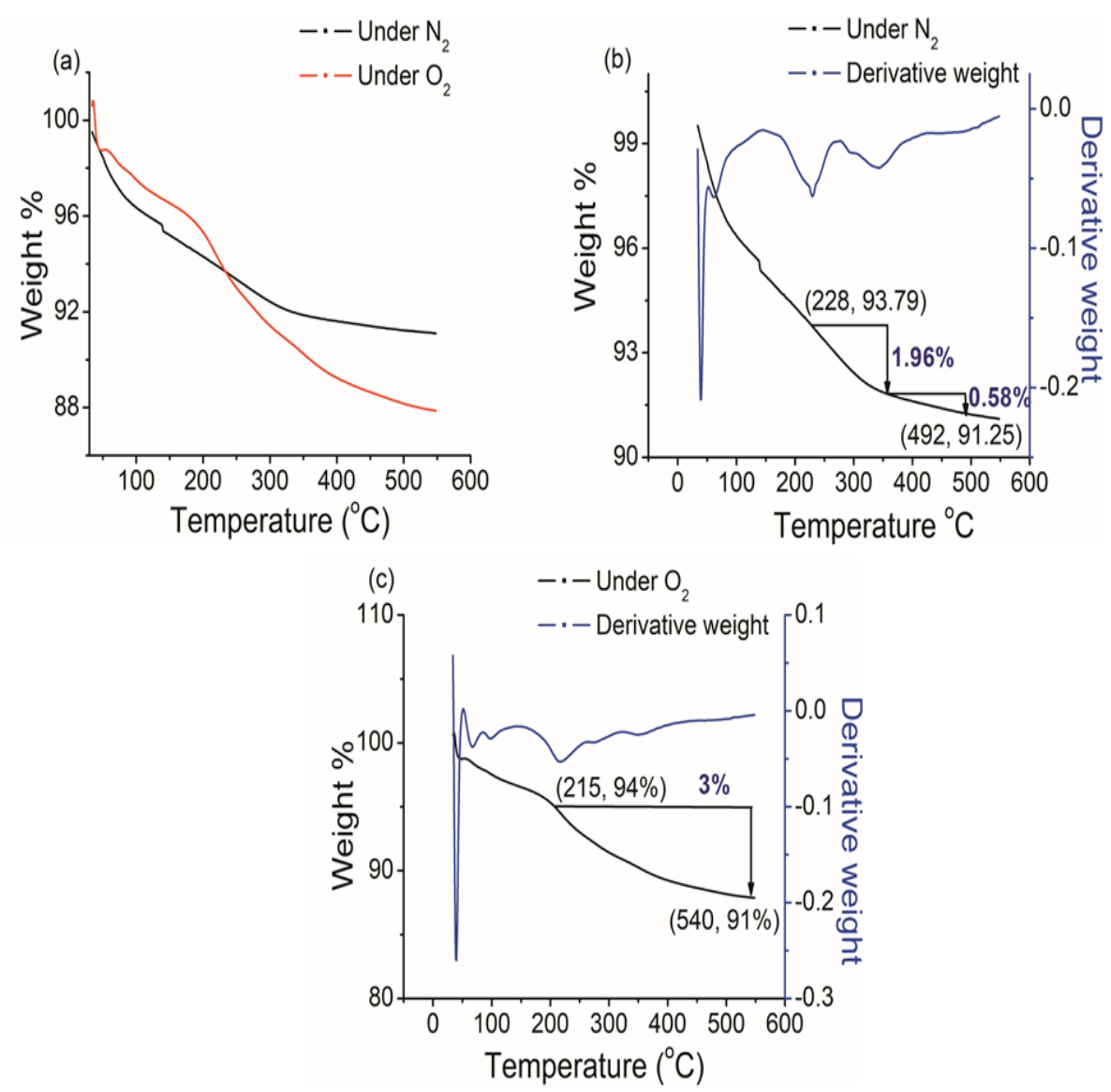

Figure 5: Thermogravimetric curves for the decomposition of washed PHAP (a) Percentage weight loss as a function of temperature, (b) and (c) Derivatives of the weight loss temperature curves

Further, the specific surface area of PHAP was measured by Beckman Coulter Sorption Analysis and it was found that surface area of PHAP is $41.3 \mathrm{~m}^{2} / \mathrm{g}$. The $\mathrm{X}$ ray powder diffraction pattern of porous nanohydroxyapatite is given in Figure 6 and it contains peaks at $2 \Theta$ positions of 26, 31, 32, 34,39 and $50^{\circ}$ and the results are in good agreement with hydroxyapatite [56][60]. 


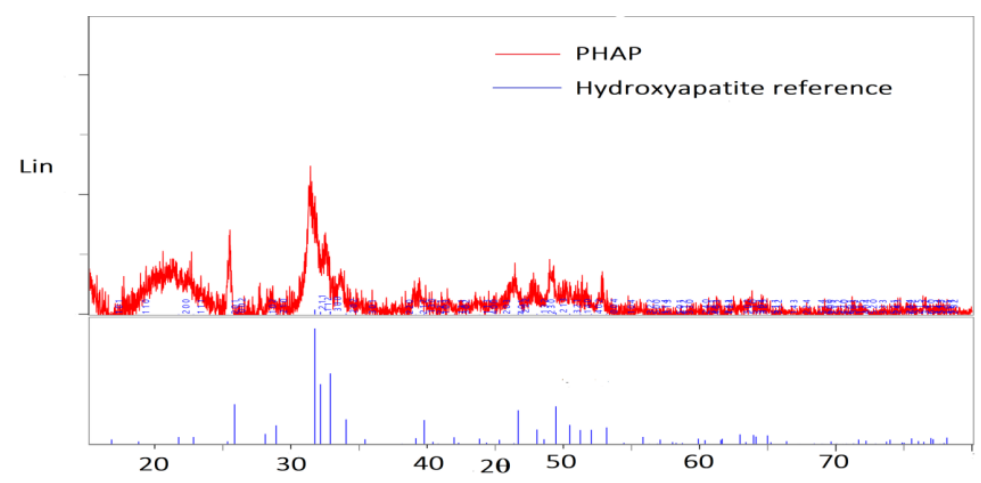

Figure 6: XRD spectrum of PHAP

3.2 The influence of microwave energy and temperature on the adsorption process of fluoride onto PHAP

Adsorption of fluoride by nanohydroxyapatite at neutral $\mathrm{pH}$ is shown in Figure 7. It can be observed that the rate of $\mathrm{F}^{-}$adsorption increases with increasing temperature and levels off around $1.2 \mathrm{mg} \mathrm{g}^{-}$ ${ }^{1}$ at $5 \mathrm{ppm}$ initial fluoride concentration. It can also be observed that the system takes a long time to reach equilibrium at room temperature. The strong dependence of fluoride adsorption on

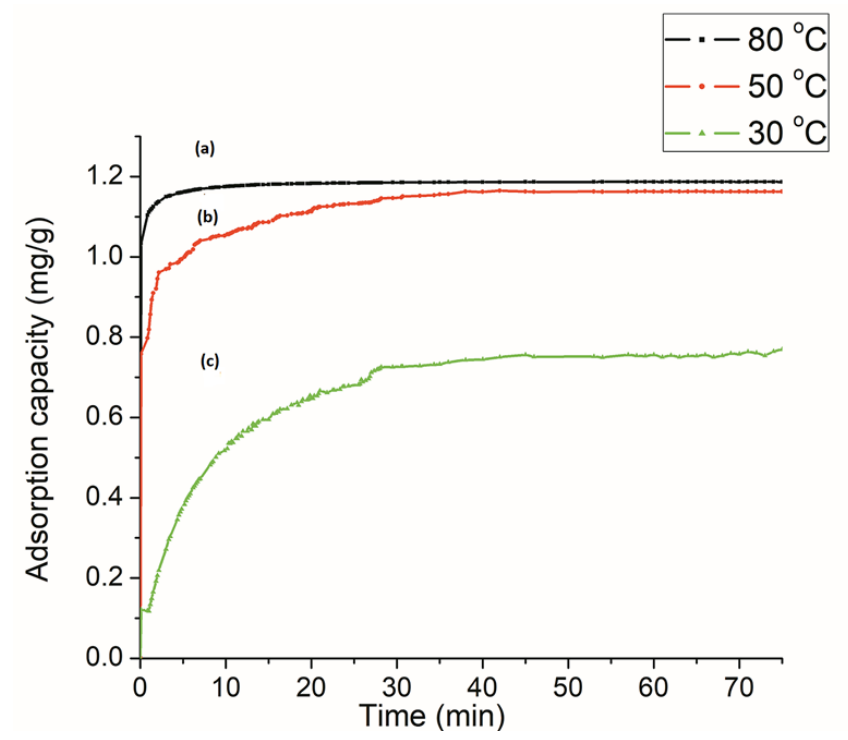

Figure 7: The amount of fluoride adsorbed vs. time at $5 \mathrm{ppm}$ initial fluoride concentration at (a) $80{ }^{\circ} \mathrm{C}$, (b) $50{ }^{\circ} \mathrm{C}$ and (c) $30^{\circ} \mathrm{C}$

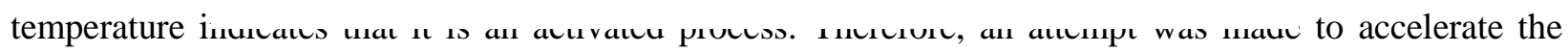
process by providing microwave irradiation. The system was exposed to microwave radiation (180 W) for $80 \mathrm{~s}$ and the adsorption of fluoride was monitored. 
Effects of various treatments on luoride adsorption is shown in Figure 8. It can be observed that the exposure to microwave energy dramatically increases the rate of fluoride adsorption. It was also worth noticing that, with normal stirring mode at $5 \mathrm{ppm}$ initial fluoride level, the system required more than $5 \mathrm{~min}$ at $80{ }^{\circ} \mathrm{C}$ to reach its equilibrium capacity of $1.2 \mathrm{mg} \mathrm{g}^{-1}$ (Figure 8), whereas, with microwave energy, it took only one minute to reach the capacity of $1.35 \mathrm{mg} \mathrm{g}^{-1}$. We can suggest two reasons for the increased adsorption of $\mathrm{F}^{-}$under microwave treatment. When the fluoride-

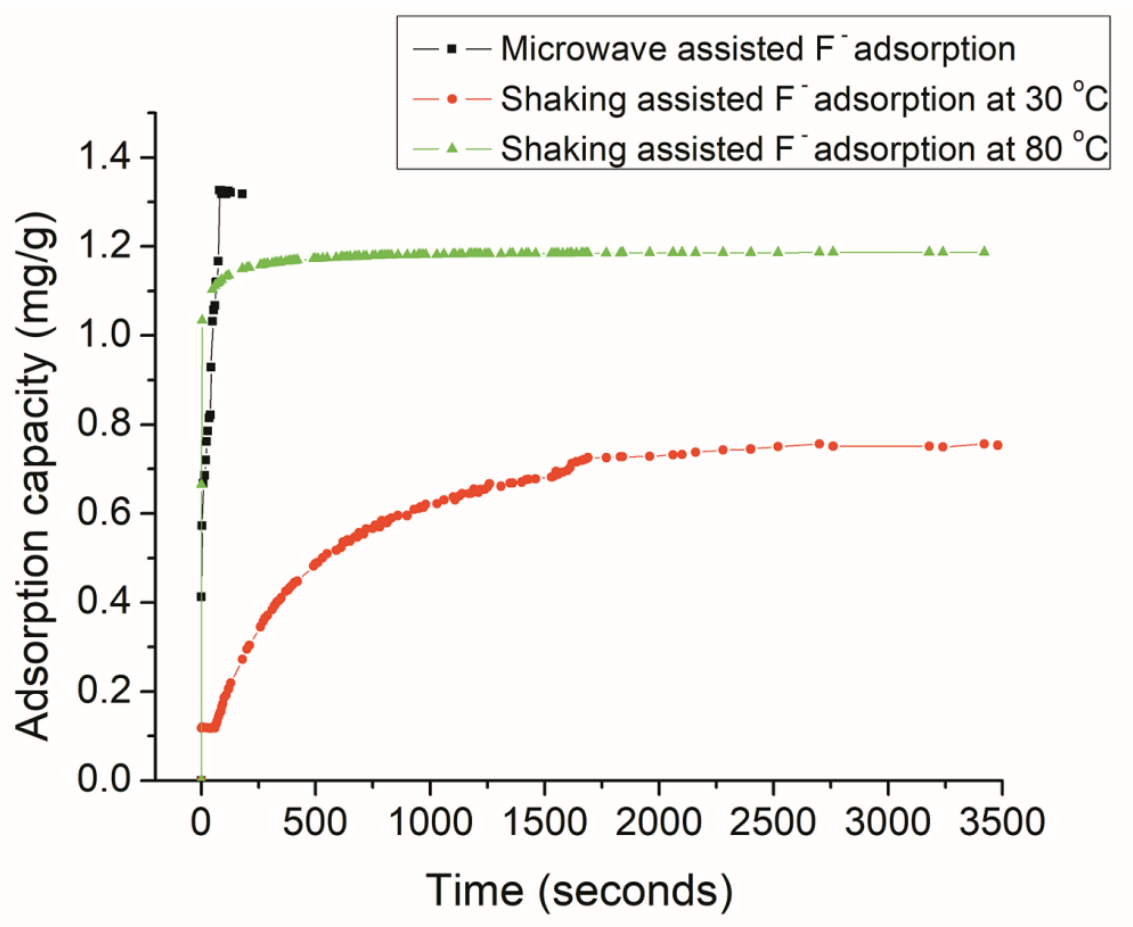

Figure 8: The effect of different methods on the equilibrium time and adsorption capacity of PHAP

nanohydroxyapatite aqueous system is subjected to microwave irradiation, molecular dipole rotations occur. These rotating water molecules can push, pull or collide with other molecules and thereby distribute the dielectric heating energy to adjacent fluoride ions to overcome the activation energy barrier. In addition, increased oscillations and collisions of water molecules in the hydration sphere of fluoride may temporarily expose $\mathrm{F}^{-}$ions to HAP surface to promote the adsorption.

\subsection{Influence of $\mathrm{pH}$ on the fluoride uptake capacity}

The influence of $\mathrm{pH}$ on the fluoride removal by nanohydroxyapatite was investigated in the $\mathrm{pH}$ range of 1-13. As shown in Figure 9, the equilibrium sorption capacity increased with increasing $\mathrm{pH}$ and reached a maximum at $\mathrm{pH}=6.5$ which is equal to $\mathrm{pH}$ of drinking water. Less fluoride adsorption at low $\mathrm{pH}$ can be attributed to the dissolution of apatite as shown in equation (2), resulting 
unstable sorbent surface as well as having increased competition for $\mathrm{F}^{-}$ions due to the releasing of $\mathrm{HPO}_{4}{ }^{2-}$

$$
\mathrm{Ca}_{10}\left(\mathrm{PO}_{4}\right)_{6}(\mathrm{OH})_{2}+8 \mathrm{H}^{+} \quad \rightleftharpoons \quad 10 \mathrm{Ca}^{2+}+6 \mathrm{HPO}_{4}{ }^{2-}+2 \mathrm{H}_{2} \mathrm{O}
$$

At extremely high $\mathrm{pH}$, competition of hydroxide ions causes a slight decrease in fluoride adsorption.

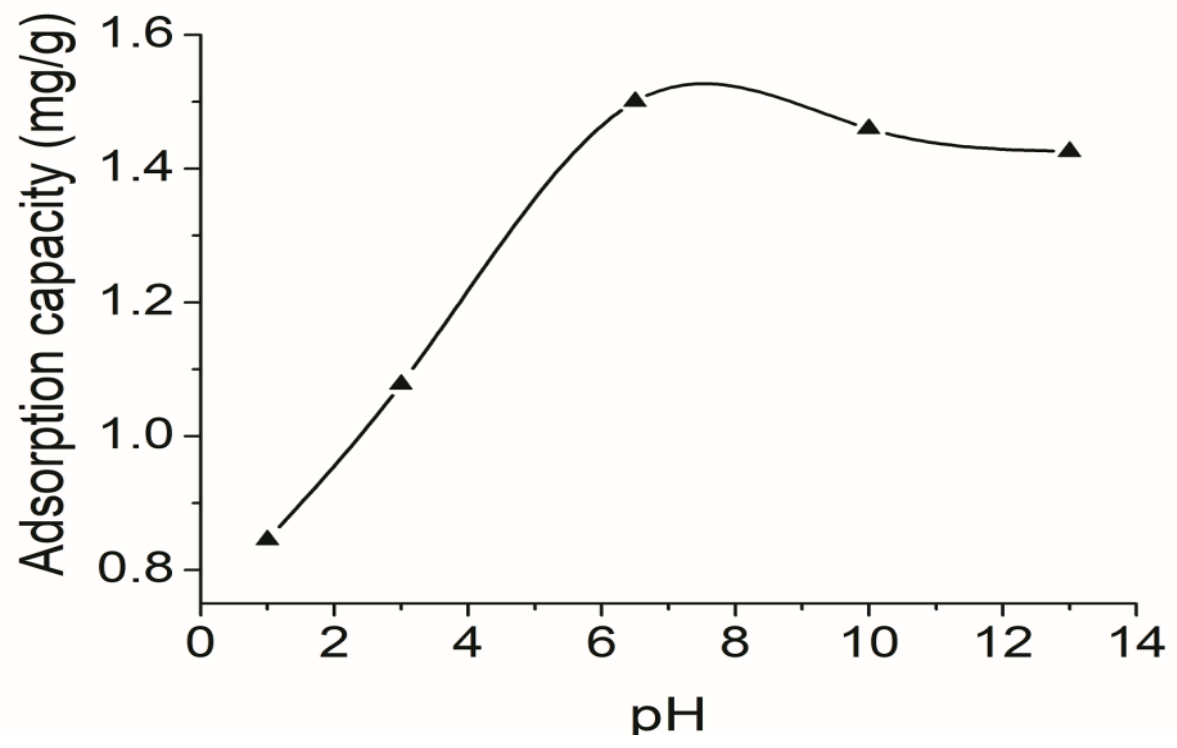

Figure 9: Effect of solution $\mathrm{pH}$ on fluoride adsorption at $5 \mathrm{ppm}$ initial fluoride level

\subsection{Adsorption dynamics and mechanism}

As shown in Figures 2 and 3, the surface of porous nanohydroxyapatite synthesized in the presence of PVP/SDS template system is coarse. The adsorption of solute from solution by porous adsorbents is a multistep process which involves a bulk transport of solute, film transport of solute and diffusion through a hypothetical film boundary layer and finally the diffusion of solute within pores and along pore wall surfaces to an active adsorption sites [61].

Therefore, when fluoride-hydroxyapatite system is subjected to microwave irradiation, the energy transfer via collisions could accelerate the diffusion/adsorption processes. To our knowledge, the enhancement of fluoride adsorption by microwave radiation has not been reported previously. Efficacy of sorption depends on sorption capacity and sorption rate. These are useful parameters and can be determined from a kinetic 
analysis of the system. These kinetic data are useful in designing fast and effective sorption systems for fluoride removal. The fluoride-porous nanohydroxyapatite system was studied using four kinetic models namely, Lagergren-first-order model, Ho's pseudo-second-order model, Weber's and Morris's intraparticle diffusion model and Boyd's model[62][63].

The integrated form of Lagergren-first-order rate expression can be presented as follows:

$$
\ln \left(q_{e}-q_{t}\right)=\ln q_{e}-k_{1} t
$$

Where $\mathrm{q}_{\mathrm{e}}$ and $\mathrm{q}_{\mathrm{t}}$ are the amounts of fluoride adsorbed $(\mathrm{mg} / \mathrm{g})$ at equilibrium and at time $\mathrm{t}$, respectively and $\mathrm{k}_{1}$ is the rate constant of the adsorption process.

The integrated form of the pseudo second order kinetic model is as follows:

$$
\frac{\mathrm{t}}{q_{t}}=\frac{1}{k_{2} q_{e}^{2}}+\frac{\mathrm{t}}{q_{e}}
$$

Where $\mathrm{q}_{\mathrm{e}}$ and $\mathrm{q}_{\mathrm{t}}$ are the amounts of fluoride adsorbed $(\mathrm{mg} / \mathrm{g})$ at equilibrium and at time $\mathrm{t}$, respectively and $k_{2}$ is the rate constant of pseudo second order adsorption process [53-55]. The kinetics of fluoride adsorption was tested by fitting data to the models described above and the results are reported in Tables 1 and 2. It can be seen that the adsorption of fluoride onto PHAP agrees well with pseudo second order kinetic model.

The kinetic data were also fitted to the Boyd's film diffusion model and intra particle diffusion model of Morris and Weber in order to obtain an insight into the mechanism and rate determining steps of fluoride adsorption.

The Boyd film diffusion model can be used to investigate whether the main resistance to mass transfer is the diffusion through the boundary layer surrounding the adsorbent particle, or the resistance to diffusion inside the pores [67-69]. This model is given by the equation:

$$
F=1-\frac{6}{\pi^{2}} \sum_{n=1}^{\infty} \frac{1}{n^{2}} \exp \left(-n^{2} B_{t}\right)
$$


Where, $B_{t}$ is the rate coefficient and $\mathrm{F}$ is fractional attainment of equilibrium at time $t$. In this model, $\mathrm{B}_{\mathrm{t}}$ is taken to be a function of $\mathrm{F}$.

$$
F=\frac{q_{t}}{q_{e}}
$$

Where $\mathrm{q}_{\mathrm{e}}$ and $\mathrm{q}_{\mathrm{t}}$ are the amounts of fluoride adsorbed (mg/g) at equilibrium and at time $\mathrm{t}$, respectively. The Fourier transformation of Boyd equation generates the following two relations:

$$
\begin{aligned}
& B_{t}=\left(\sqrt{\pi}-\sqrt{\pi-\left(\frac{\pi^{2} F}{3}\right)}\right)^{2} \text { For } \mathrm{F}<0.85 \\
& B_{t}=-0.4977-\ln (1-F) \text { or } \mathrm{F}>0.85
\end{aligned}
$$

Where the rate coefficient $B_{t}$ is related to the effective diffusion coefficient $\left(D_{e}\right)$ and the particle radius (r) as given in the following equation:

$$
B_{t}=\frac{\pi^{2} D_{e}}{r^{2}}
$$

Where, the shape of the particle has been assumed as spherical.

A plot between time and $\mathrm{B}_{\mathrm{t}}$ is used to explain the adsorption mechanism. If the plot is linear and passes through the origin, the rate of mass transfer is assumed to be controlled by the pore diffusion. If the plot is nonlinear or linear but does not pass through the origin, the adsorption process is assumed to be controlled by a chemical reaction or film diffusion process.

Intraparticle diffusion model investigates whether the intraparticle diffusion of solute is the rate determining step. In this case, the rate is partially a function of the pore size distribution of the adsorbent and the structure of the solute. The intraparticle diffusion model is described by the equation below:

$$
q_{t}=k_{i n} t^{0.5}
$$


Where $\mathrm{q}_{\mathrm{t}}(\mathrm{mg} / \mathrm{g})$ is the adsorption capacity at time $\mathrm{t}, \mathrm{k}_{\mathrm{in}}\left(\mathrm{mg} / \mathrm{g} \mathrm{min}^{-0.5}\right)$ is the intraparticle diffusion rate constant and $\mathrm{t}^{0.5}$ is the square root of time.[70]

The intra particle diffusion coefficient (D) can be calculated from the following equation [71],

$$
k_{\text {in }}=\frac{6 q_{e}}{R} \sqrt{\frac{D}{\pi}}
$$

Where $\mathrm{R}(\mathrm{cm})$ is the particle radius, $\mathrm{q}_{\mathrm{e}}(\mathrm{mg} / \mathrm{g})$ is the adsorption capacity at equilibrium. D was calculated by assuming all the particles are spherical in shape. In this case, the slope of $\mathrm{q}_{\mathrm{t}}$ versus $\mathrm{t}^{0.5}$ graph gives $\mathrm{k}_{\text {in }}$ and the average particle radius was determined by analyzing TEM images.

In order to predict the mechanism of fluoride adsorption onto PHAP, the kinetic data were analysed by the kinetic models described above. The values of kinetic parameters and correlation coefficients obtained with the models are listed in Tables 1 and 2 . The best correlation was obtained with the pseudo second order model for the adsorption of fluoride onto nanohydroxyapatite. The graphs in Figure 10 show the agreement of experimental data with the second order kinetic model at three different temperatures.

Table 1: Parameters of Lagergren-first-order and Pseudo second order for fluoride adsorption from 5 ppm initial fluoride solution

\begin{tabular}{|c|c|c|c|c|}
\hline \multirow[t]{2}{*}{ Kinetic models } & \multirow[t]{2}{*}{ Parameters } & \multicolumn{3}{|c|}{ Temperature } \\
\hline & & $80^{\circ} \mathrm{C}$ & $50^{\circ} \mathrm{C}$ & $30^{\circ} \mathrm{C}$ \\
\hline \multirow[t]{3}{*}{ Lagergren-first-order } & $\mathrm{q}_{\mathrm{e}}\left(\mathrm{mg} \mathrm{g}^{-1}\right)$ & 0.05 & 0.31 & 0.67 \\
\hline & $\mathrm{k}_{1}\left(\min ^{-1}\right)$ & 0.12 & 0.09 & 0.06 \\
\hline & $\mathrm{R}^{2}$ & 0.9176 & 0.9433 & 0.9657 \\
\hline Pseudo second order ( $\mathrm{t} / \mathrm{q}_{\mathrm{t}}$ vs. $\left.\mathrm{t}\right)$ & $\mathrm{q}_{\mathrm{e}}\left(\mathrm{mg} \mathrm{g}^{-1}\right)$ & 1.19 & 1.13 & 0.79 \\
\hline
\end{tabular}




\begin{tabular}{|l|l|l|l|l|}
\hline & $\mathrm{k}_{2}\left(\mathrm{~min}^{-1}\right)$ & 8.86 & 1.62 & 0.27 \\
\cline { 2 - 5 } & $\mathrm{R}^{2}$ & 0.9999 & 0.9992 & 0.9796 \\
\hline $\begin{array}{l}\text { Experimental adsorption } \\
\text { capacity (qe) for 5ppm fluoride } \\
\text { solution }\end{array}$ & $\mathrm{q}_{\mathrm{e}}\left(\mathrm{mg} \mathrm{g}^{-1}\right)$ & 1.26 & & \\
\hline
\end{tabular}

Table 2: Parameters of Intra particle diffusion and Boyd's model for fluoride adsorption by PHAP from 5 ppm initial fluoride solution

\begin{tabular}{|l|l|l|l|l|}
\hline \multicolumn{5}{|l|}{ Boyd's model } \\
\hline $\begin{array}{l}\text { Temperature } \\
\left({ }^{\circ} \mathrm{C}\right)\end{array}$ & $\begin{array}{l}\mathrm{B} \\
\left(\mathrm{min}^{-1}\right)\end{array}$ & $\begin{array}{l}\mathrm{D}_{\text {eff. }} \\
\left(\mathrm{cm}^{2} \mathrm{~min}^{-1}\right)^{*} 10^{-13}\end{array}$ & $\mathrm{R}^{2}$ & $\begin{array}{l}\text { Intercept/thickness of } \\
\text { boundary layer }\end{array}$ \\
\hline 30 & 0.02 & 1.2 & 0.99 & -0.03 \\
\hline 50 & 0.091 & 2.3 & 0.92 & 0.91 \\
\hline 80 & 0.15 & 3.7 & 0.96 & 2.52 \\
\hline Intra particle diffusion model & $\begin{array}{l}\mathrm{k}_{\text {in }} \\
(\mathrm{mg} / \mathrm{gmin}\end{array}$ & $\begin{array}{l}\mathrm{D} / 2 \\
\left(\mathrm{~cm}^{2} \mathrm{~min}^{-1}\right)^{*} 10^{-14}\end{array}$ & $\mathrm{R}^{2}$ & $\begin{array}{l}\text { Intercept/thickness } \\
\text { boundary layer }\end{array}$ \\
\hline $\begin{array}{l}\text { Temperature } \\
\left({ }^{\circ} \mathrm{C}\right)\end{array}$ & 0.15 & 2.45 & 0.97 & 0.02 \\
\hline 30 & 0.07 & 0.35 & 0.90 & 0.84 \\
\hline 50 & 0.02 & 0.022 & 0.74 & 1.10 \\
\hline 80 & & & & \\
\hline
\end{tabular}

It has been reported that there are three possible mechanisms to explain the uptake of free fluorides by nanohydroxyapatite. They are the substitution into the crystal lattice, adsorption on the surface, and precipitation. The mechanism of fluoride uptake and efficiency of fluoride removal are strongly dependent on the morphology of PHAP and chemical composition of water $(\mathrm{pH}$, concentration of ions in solution) [72,73]. As the ionic radii of fluoride (1.36 $\AA$ ) and hydroxyl (1.40 $\AA$ ) are comparable, the substitution of hydroxyl by fluoride in the hydroxyapatite lattice is not sterically hindered. The centre of the calcium triangles in the hydroxyapatite lattice can comfortably accommodate the fluoride ion due to its small size. Furthermore, the substitution of fluoride at the centre of calcium triangle eliminates the electric dipole present in the lattice due to off centred 
position occupied by hydroxyl ion yielding a thermodynamically more stable lattice structure. Although, the surface charge plays an important role on the adsorption of fluoride, it has been reported that the fluoride adsorption by nanohydroxyapatite is mainly controlled by the diffusion of fluoride into the hydroxyapatite crystal [72,73].
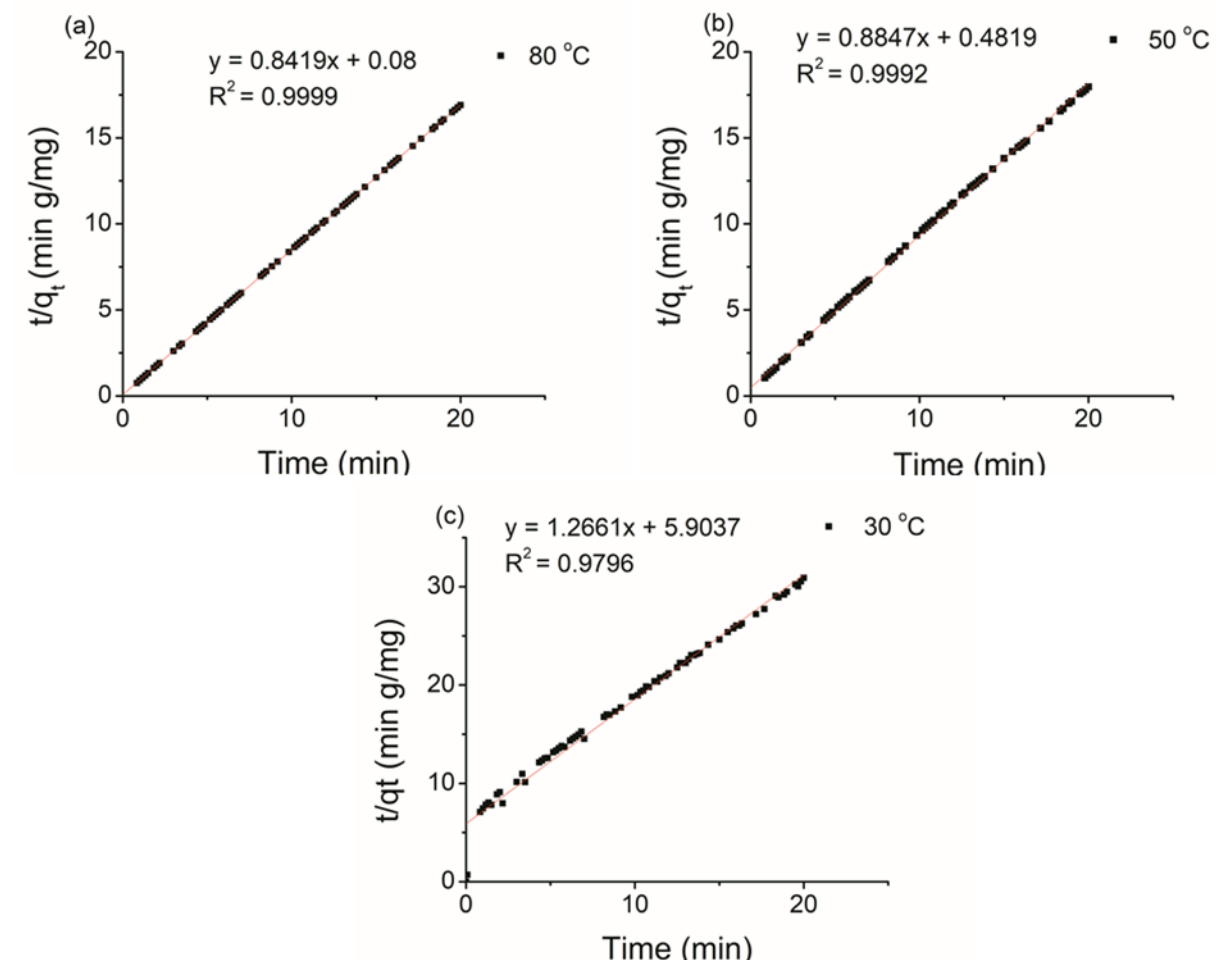

Figure 10: Pseudo second order kinetic model at three different temperatures, (a) at $80{ }^{\circ} \mathrm{C}$ (b) at $50{ }^{\circ} \mathrm{C}(\mathrm{c})$ at $30{ }^{\circ} \mathrm{C}$

\subsection{Temperature dependence and activation energy}

The fluoride adsorption rate increases with increasing temperature, indicating that this process is an activated process. Therefore, the Arrhenius equation was used to estimate the apparent activation energy of adsorption process [74].

$$
k=A e^{\frac{-E_{a}}{R T}}
$$

Where $\mathrm{k}$ is the rate constant, $\mathrm{A}$ is the Frequency factor, $\mathrm{E}_{\mathrm{a}}$ is the activation energy, $\mathrm{T}$ is the temperature in kelvin and $\mathrm{R}$ is the universal gas constant.

The apparent activation energy calculated using Arrhenius equation for the fluoride adsorption by nanohydroxyapatite (Figure 11) is $63.1 \mathrm{kJmol}^{-1}$. 


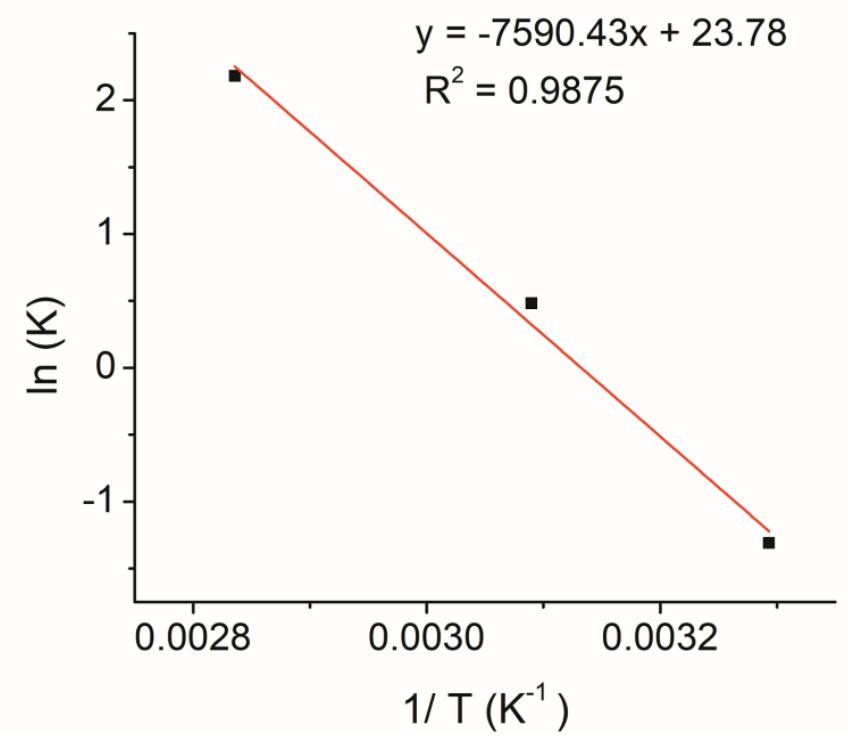

Figure 91: Arrhenius plot for fluoride adsorption onto PHAP

\subsection{Adsorption isotherms}

The adsorption isotherm models such as Langmuir and Freundlich can be used to describe the adsorption process at equilibrium [62]. The Langmuir isotherm equation describes the formation of a saturated monolayer of adsorbate on the surface of the adsorbent at the equilibrium. In order to apply this model, the surface of the adsorbate should have energetically equivalent and identical binding sites.

The simplified form of the Langmuir isotherm equation can be expressed as,

$$
\frac{C_{e}}{q_{e}}=\frac{C_{e}}{q_{m}}+\frac{1}{K q_{m}}
$$


Where $C_{e}(\mathrm{mg} / \mathrm{L})$ is equilibrium fluoride concentration, $\mathrm{q}_{\mathrm{e}}$ is the equilibrium amount of fluoride adsorbed, $\mathrm{q}_{\mathrm{m}}$ is the maximum adsorption capacity of the adsorbent and $\mathrm{K}\left(\mathrm{L} \mathrm{mg}^{-1}\right)$ is the equilibrium constant of the adsorption process.

The Freundlich adsorption isotherm explains the adsorption process at equilibrium on a heterogeneous surface. The Freundlich isotherm equation in linear form can be expressed as,

$$
\ln q_{e}=\ln K_{f}+\frac{1}{n} \ln C_{e}
$$

Where $C_{e}(m g / L)$ is equilibrium fluoride concentration, $q_{e}$ is amount of fluoride adsorbed at the equilibrium $\mathrm{K}_{\mathrm{f}}(\mathrm{L} / \mathrm{mg})$ is the empirical constant of Freundlich isotherm which depends on temperature and $\mathrm{n}$ is the empirical parameter related to the intensity of adsorption. Values of " $\mathrm{n}$ between 1 and 10 can be considered as a favourable conditions for adsorption [75].
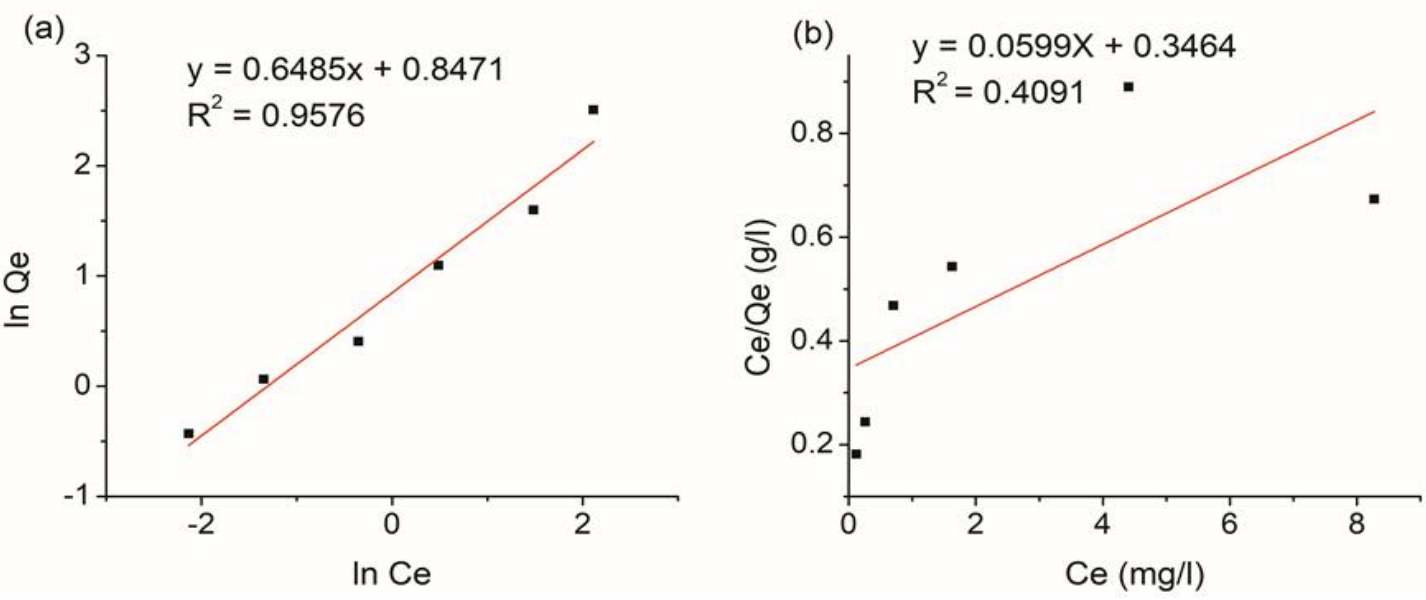

Figure 12: Sorption isotherms for Fluoride adsorption onto PHAP (a) Freundlich isothermal model (b) Langmuir model

The experimental data fitted to Langmuir and Freundlich isotherm models are shown in Figure 12 and a better agreement of experimental data to Freundlich model is revealed. The parameters of isotherms are given in Table 3. These results show that the adsorption occurs on a heterogeneous surface and the binding sites of PHAP for fluoride ions are not energetically equivalent. Accordingly, the adsorption capacity was found to be $9.19 \mathrm{mg} / \mathrm{g}$. In addition, the reported material was engineered in such a way that it could efficiently adsorb fluoride at the $\mathrm{pH}$ of drinking water. It is also worth mentioning that this material showed high adsorption capacities $(54 \mathrm{mg} / \mathrm{g})$ at high fluoride concentrations (200 ppm) and also it can reached the equilibrium within $80 \mathrm{~s}$ at drinking water $\mathrm{pH}$ (Supporting document S2). In contrast to our investigation, many of the synthesized 
adsorbents to remove $\mathrm{F}^{-}$in reported data, to date show their highest capacities at very low $\mathrm{pH}$ diminishing their applicability in real drinking water applications

Table 3: Isotherm parameters of PHAP

\begin{tabular}{|l|l|l|}
\hline $\begin{array}{l}\text { Experimental data at 20 ppm initial fluoride } \\
\text { concentration }\end{array}$ & $\mathrm{q}_{\mathrm{e}}(\mathrm{mg} / \mathrm{g})$ & 12.29 \\
\hline Langmuir model & & \\
\hline \multirow{5}{*}{ Freundlich model } & $\mathrm{q}_{\mathrm{e}}(\mathrm{mg} / \mathrm{g})$ & 16.69 \\
\cline { 2 - 3 } & $\mathrm{K}_{1}\left(\mathrm{~min}^{-1}\right)$ & 0.17 \\
\cline { 2 - 3 } & $\mathrm{R}^{2}$ & 0.41 \\
\hline & $\mathrm{q}_{\mathrm{e}}(\mathrm{mg} / \mathrm{g})$ & 9.19 \\
\cline { 2 - 3 } & $\mathrm{K}_{\mathrm{f}}\left(\mathrm{g} \mathrm{mg}^{-1} \mathrm{~min}^{-1}\right)$ & 2.33 \\
\cline { 2 - 3 } & $\mathrm{R}^{2}$ & 0.96 \\
\hline & $\mathrm{n}$ & 1.54 \\
\hline
\end{tabular}

The adsorption capacities, initial concentrations, $\mathrm{pH}$ and time taken to reach the equilibrium for reported materials are summarized in Table 4. According to these data, our material reached equilibrium within $80 \mathrm{~s}$ under the influence of microwave and this value is the fastest ever recorded for fluoride adsorption.

Table 4: The adsorption conditions reported for already published materials

\begin{tabular}{|c|c|c|c|c|c|c|}
\hline Material & $\begin{array}{l}\text { Shaking } \\
\text { time }\end{array}$ & pH & $\begin{array}{l}\text { Initial } \\
\text { concentration } \\
\text { which was used } \\
\text { for adsorption } \\
\text { isotherms }(\mathrm{mg} / \mathrm{L})\end{array}$ & $\begin{array}{l}\text { Maximum } \\
\text { adsorption } \\
\text { capacity } \\
(\mathrm{mg} / \mathrm{g})\end{array}$ & $\begin{array}{l}\text { Adsorption } \\
\text { isotherm model }\end{array}$ & Reference \\
\hline $\begin{array}{l}\text { GC } \\
(\mathrm{FeSO} 4 \cdot 7 \mathrm{H} 2 \mathrm{O}) \\
\mathrm{GC}(\mathrm{Fe} 2 \mathrm{O} 3)\end{array}$ & $\begin{array}{l}48 \text { hours } \\
48 \text { hours }\end{array}$ & $\begin{array}{l}6.9 \\
6.9\end{array}$ & $\begin{array}{l}5-50 \\
5-50\end{array}$ & $\begin{array}{l}2.16 \\
1.7\end{array}$ & Langmuir model & [62] \\
\hline $\begin{array}{l}\mathrm{CeO}_{2}-\mathrm{ZrO}_{2} \\
\text { nanocages }\end{array}$ & 24 hours & 4 & $1-100$ & 175 & Langmuir model & [76] \\
\hline $\begin{array}{l}\mathrm{CeO}_{2} / \mathrm{Mg}-\mathrm{Fe} \\
\text { layered double } \\
\text { hydroxides }\end{array}$ & 24 hours & $6-7$ & $20-200$ & 60.4 & Langmuir model & [32] \\
\hline $\begin{array}{l}\text { Mineral- } \\
\text { substituted } \\
\text { hydroxyapatite }\end{array}$ & 60 minutes & 3 & 10 & 8.36 & Langmuir model & [77] \\
\hline $\begin{array}{l}\text { Porous } \\
\text { nanohydroxyapatit } \\
\text { e } \\
\end{array}$ & $\begin{array}{l}80 \text { seconds } \\
80 \text { seconds } \\
\end{array}$ & $\begin{array}{l}6.8 \\
6.8 \\
\end{array}$ & $\begin{array}{l}1-20 \\
200\end{array}$ & $\begin{array}{l}9.19 \\
54 \\
\end{array}$ & Freundlich model & $\begin{array}{l}\text { (This } \\
\text { work) }\end{array}$ \\
\hline
\end{tabular}




\section{Conclusion}

Porous hydroxyapatite (PHAP) was successfully synthesized using PVP-SDS template system. The fluoride adsorption on porous nanohydroxyapatite was an activated process which followed second order kinetics and could be accelerated using microwave energy. The time taken to reach the equilibrium (more than $15 \mathrm{~min}$ at $30^{\circ} \mathrm{C}$ ) could be reduced to $80 \mathrm{~s}$ by exposing to microwave irradiation providing the fastest $\mathrm{F}^{-}$adsorption system for ever recorded. As PHAP shows its highest capacity at $\mathrm{pH} 6-7$, this system has a very high potential in defluorination of drinking water.

\section{Acknowledgements}

The authors gratefully acknowledge the National Research Council Sri Lanka (NRC TO 16-18) for the financial support provided and the Sri Lanka Institute of Nanotechnology for conducting the Transmission Electron microscope (TEM) and Scanning electron microscope (SEM) studies.

\section{Appendix A. Supplementary data}

\section{References}

[1] M. Mohapatra, S. Anand, B.K. Mishra, D.E. Giles, P. Singh, Review of fluoride removal from drinking water, J. Environ. Manage. 91 (2009) 67-77. doi:10.1016/j.jenvman.2009.08.015.

[2] H. Liu, S. Deng, Z. Li, G. Yu, J. Huang, Preparation of Al-Ce hybrid adsorbent and its application for defluoridation of drinking water, J. Hazard. Mater. 179 (2010) 424-430. doi:10.1016/j.jhazmat.2010.03.021.

[3] S. Dey, S. Goswami, U.C. Ghosh, Hydrous ferric oxide (HFO) - A scavenger for fluoride from contaminated water, 2004. doi:10.1023/B:WATE.0000044854.71497.b6.

[4] V. Dhar, M. Bhatnagar, Physiology and toxicity of fluoride, Indian J. Dent. Res. 20 (2009) 350. doi:10.4103/0970-9290.57379.

[5] J. Aaseth, M. Shimshi, J.L. Gabrilove, G.S. Birketvedt, Fluoride: A toxic or therapeutic agent in the treatment of osteoporosis?, J. Trace Elem. Exp. Med. 17 (2004) 83-92. doi:10.1002/jtra.10051.

[6] D. Chakraborti, M.M. Rahman, A. Chatterjee, D. Das, B. Das, B. Nayak, A. Pal, U.K. Chowdhury, S. Ahmed, B.K. Biswas, M.K. Sengupta, D. Lodh, G. Samanta, S. Chakraborty, M.M. Roy, R.N. 
Dutta, K.C. Saha, S.C. Mukherjee, S. Pati, P.B. Kar, Fate of over 480 million inhabitants living in arsenic and fluoride endemic Indian districts: Magnitude, health, socio-economic effects and mitigation approaches, J. Trace Elem. Med. Biol. 38 (2016) 33-45. doi:10.1016/J.JTEMB.2016.05.001.

[7] A.S. Kraus, W.F. Forbes, Aluminum, fluoride and the prevention of Alzheimer's disease., Can. J. Public Health. 83 (n.d.) 97-100. http://www.ncbi.nlm.nih.gov/pubmed/1617567 (accessed February 26, 2019).

[8] A. Bhatnagar, E. Kumar, M. Sillanpää, Fluoride removal from water by adsorption-A review, Chem. Eng. J. 171 (2011) 811-840. doi:10.1016/j.cej.2011.05.028.

[9] X. Xiong, J. Liu, W. He, T. Xia, P. He, X. Chen, K. Yang, A. Wang, Dose-effect relationship between drinking water fluoride levels and damage to liver and kidney functions in children, Environ. Res. 103 (2007) 112-116. doi:10.1016/j.envres.2006.05.008.

[10] S. Wickramarathna, S. Balasooriya, S. Diyabalanage, R. Chandrajith, Tracing environmental aetiological factors of chronic kidney diseases in the dry zone of Sri Lanka-A hydrogeochemical and isotope approach, J. Trace Elem. Med. Biol. 44 (2017) 298-306. doi:10.1016/j.jtemb.2017.08.013.

[11] W.B. Apambire, D.R. Boyle, F.A. Michel, Geochemistry, genesis, and health implications of fluoriferous groundwaters in the upper regions of Ghana, Environ. Geol. 33 (1997) 13-24. doi:10.1007/s002540050221.

[12] E.J. Reardon, Y. Wang, A Limestone Reactor for Fluoride Removal from Wastewaters, Environ. Sci. Technol. 34 (2000) 3247-3253. doi:10.1021/es990542k.

[13] H. Huang, J. Liu, P. Zhang, D. Zhang, F. Gao, Investigation on the simultaneous removal of fluoride, ammonia nitrogen and phosphate from semiconductor wastewater using chemical precipitation, Chem. Eng. J. 307 (2017) 696-706. doi:10.1016/J.CEJ.2016.08.134.

[14] X. Fan, D.J. Parker, M.D. Smith, Adsorption kinetics of fluoride on low cost materials, Water Res. 37 (2003) 4929-4937. doi:10.1016/J.WATRES.2003.08.014.

[15] N. Das, P. Pattanaik, R. Das, Defluoridation of drinking water using activated titanium rich bauxite, J. Colloid Interface Sci. 292 (2005) 1-10. doi:10.1016/j.jcis.2005.06.045.

[16] P.I. Ndiaye, P. Moulin, L. Dominguez, J.C. Millet, F. Charbit, Removal of fluoride from electronic 
industrial effluentby RO membrane separation, Desalination. 173 (2005) 25-32. doi:10.1016/J.DESAL.2004.07.042.

[17] N.L. Le, S.P. Nunes, Materials and membrane technologies for water and energy sustainability, Sustain. Mater. Technol. 7 (2016) 1-28. doi:10.1016/J.SUSMAT.2016.02.001.

[18] M. Arora, R.C. Maheshwari, S.K. Jain, A. Gupta, Use of membrane technology for potable water production, Desalination. 170 (2004) 105-112. doi:10.1016/J.DESAL.2004.02.096.

[19] K. Hu, J.M. Dickson, Nanofiltration membrane performance on fluoride removal from water, J. Memb. Sci. 279 (2006) 529-538. doi:10.1016/J.MEMSCI.2005.12.047.

[20] A. Boubakri, N. Helali, M. Tlili, M. Ben Amor, Fluoride removal from diluted solutions by Donnan dialysis using full factorial design, Korean J. Chem. Eng. 31 (2014) 461-466. doi:10.1007/s11814013-0263-9.

[21] N. Kabay, Ö. Arar, S. Samatya, Ü. Yüksel, M. Yüksel, Separation of fluoride from aqueous solution by electrodialysis: Effect of process parameters and other ionic species, J. Hazard. Mater. 153 (2008) 107-113. doi:10.1016/J.JHAZMAT.2007.08.024.

[22] S.M. Maliyekkal, A.K. Sharma, L. Philip, Manganese-oxide-coated alumina: A promising sorbent for defluoridation of water, Water Res. $40 \quad$ (2006) 3497-3506. doi:10.1016/J.WATRES.2006.08.007.

[23] A. Teutli-Sequeira, V. Martínez-Miranda, M. Solache-Ríos, I. Linares-Hernández, Aluminum and lanthanum effects in natural materials on the adsorption of fluoride ions, J. Fluor. Chem. 148 (2013) 6-13. doi:10.1016/J.JFLUCHEM.2013.01.015.

[24] Y. Nie, C. Hu, C. Kong, Enhanced fluoride adsorption using Al (III) modified calcium hydroxyapatite, J. Hazard. Mater. 233-234 (2012) 194-199. doi:10.1016/J.JHAZMAT.2012.07.020.

[25] N. Sakhare, S. Lunge, S. Rayalu, S. Bakardjiva, J. Subrt, S. Devotta, N. Labhsetwar, Defluoridation of water using calcium aluminate material, Chem. Eng. J. 203 (2012) 406-414. doi:10.1016/J.CEJ.2012.07.065.

[26] C.M. Kanno, R.L. Sanders, S.M. Flynn, G. Lessard, S.C.B. Myneni, Novel Apatite-Based Sorbent for Defluoridation: Synthesis and Sorption Characteristics of Nano-micro-crystalline Hydroxyapatite-Coated-Limestone, Environ. Sci. Technol. $48 \quad$ (2014) 5798-5807. 
doi:10.1021/es405135r.

[27] M.G. Sujana, S. Anand, Iron and aluminium based mixed hydroxides: A novel sorbent for fluoride removal from aqueous solutions, Appl. Surf. Sci. 256 (2010) 6956-6962. doi:10.1016/J.APSUSC.2010.05.006.

[28] A.I. Ndé-Tchoupé, R.A. Crane, H.T. Mwakabona, C. Noubactep, K.N. Njau, Technologies for decentralized fluoride removal: Testing metallic iron-based filters, Water (Switzerland). 7 (2015) 6750-6774. doi:10.3390/w7126657.

[29] X. Dou, Y. Zhang, H. Wang, T. Wang, Y. Wang, Performance of granular zirconium-iron oxide in the removal of fluoride from drinking water, Water Res. 45 (2011) 3571-3578. doi:10.1016/J.WATRES.2011.04.002.

[30] L. Chai, Y. Wang, N. Zhao, W. Yang, X. You, Sulfate-doped Fe3O4/Al2O3 nanoparticles as a novel adsorbent for fluoride removal from drinking water, Water Res. 47 (2013) 4040-4049. doi:10.1016/J.WATRES.2013.02.057.

[31] L.H. Velazquez-Jimenez, R.H. Hurt, J. Matos, J.R. Rangel-Mendez, Zirconium-Carbon Hybrid Sorbent for Removal of Fluoride from Water: Oxalic Acid Mediated $\mathrm{Zr}$ (IV) Assembly and Adsorption Mechanism, Environ. Sci. Technol. 48 (2014) 1166-1174. doi:10.1021/es403929b.

[32] T. Zhang, Q. Li, H. Xiao, Z. Mei, H. Lu, Y. Zhou, Enhanced fluoride removal from water by nonthermal plasma modified CeO2/Mg-Fe layered double hydroxides, Appl. Clay Sci. 72 (2013) 117123. doi:10.1016/J.CLAY.2012.12.003.

[33] T. Zhang, Q. Li, H. Xiao, H. Lu, Y. Zhou, Synthesis of Li-Al Layered Double Hydroxides (LDHs) for Efficient Fluoride Removal, Ind. Eng. Chem. Res. 51 (2012) 11490-11498. doi:10.1021/ie300863x.

[34] P.-P. Huang, C.-Y. Cao, F. Wei, Y.-B. Sun, W.-G. Song, MgAl layered double hydroxides with chloride and carbonate ions as interlayer anions for removal of arsenic and fluoride ions in water, RSC Adv. 5 (2015) 10412-10417. doi:10.1039/C4RA15160G.

[35] X. Yu, S. Tong, M. Ge, J. Zuo, Removal of fluoride from drinking water by cellulose@hydroxyapatite nanocomposites, Carbohydr. Polym. 92 (2013) 269-275. doi:10.1016/J.CARBPOL.2012.09.045.

[36] K. Pandi, N. Viswanathan, Synthesis of alginate bioencapsulated nano-hydroxyapatite composite 
for selective fluoride sorption, Carbohydr. Polym. $112 \quad$ (2014) 662-667. doi:10.1016/J.CARBPOL.2014.06.029.

[37] K. Poovendran, K.S.J. Wilson, M.S. Revathy, A. Ayeshamariam, K. Kaviyarasu, Functionalization effect of HAp with copper $(\mathrm{Cu})$ having excellent dielectric applications, Surfaces and Interfaces. 19 (2020) 100474. doi:10.1016/j.surfin.2020.100474.

[38] M.S. Fernando, R.M. De Silva, K.M.N. De Silva, Synthesis, characterization, and application of nano hydroxyapatite and nanocomposite of hydroxyapatite with granular activated carbon for the removal of $\mathrm{Pb} 2+$ from aqueous solutions, Appl. Surf. Sci. 351 (2015) 95-103. doi:10.1016/j.apsusc.2015.05.092.

[39] M. Kaviya, P. Ramakrishnan, S.B. Mohamed, R. Ramakrishnan, J. Gimbun, K.M. Veerabadran, M.R. Kuppusamy, K. Kaviyarasu, T.M. Sridhar, Synthesis and characterization of nanohydroxyapatite/graphene oxide composite materials for medical implant coating applications, Mater. Today Proc. (2020). doi:10.1016/j.matpr.2020.02.932.

[40] L.E.L. Hammari, A. Laghzizil, P. Barboux, K. Lahlil, A. Saoiabi, Retention of fluoride ions from aqueous solution using porous hydroxyapatite: Structure and conduction properties, J. Hazard. Mater. 114 (2004) 41-44. doi:10.1016/j.jhazmat.2004.06.032.

[41] W.P.S.L. Wijesinghe, M.M.M.G.P.G. Mantilaka, T.A.N. Peiris, R.M.G. Rajapakse, K.G.U. Wijayantha, H.M.T.G.A. Pitawala, T.N. Premachandra, H.M.T.U. Herath, R.P.V.J. Rajapakse, Preparation and characterization of mesoporous hydroxyapatite with non-cytotoxicity and heavy metal adsorption capacity, New J. Chem. 42 (2018) 10271-10278. doi:10.1039/c8nj00673c.

[42] D.O. Costa, S.J. Dixon, A.S. Rizkalla, One- and Three-Dimensional Growth of Hydroxyapatite Nanowires during Sol-Gel-Hydrothermal Synthesis, ACS Appl. Mater. Interfaces. 4 (2012) 14901499. doi:10.1021/am201735k.

[43] Y. Zhang, L. Zhou, D. Li, N. Xue, X. Xu, J. Li, Oriented nano-structured hydroxyapatite from the template, Chem. Phys. Lett. 376 (2003) 493-497. doi:10.1016/S0009-2614(03)01038-8.

[44] X.Y. Zhao, Y.J. Zhu, C. Qi, F. Chen, B.Q. Lu, J. Zhao, J. Wu, Hierarchical hollow hydroxyapatite microspheres: Microwave-assisted rapid synthesis by using pyridoxal-5'-phosphate as a phosphorus source and application in drug delivery, Chem. - An Asian J. 8 (2013) 1313-1320. doi:10.1002/asia.201300142. 
[45] K. Lin, X. Liu, J. Chang, Y. Zhu, Facile synthesis of hydroxyapatite nanoparticles, nanowires and hollow nano-structured microspheres using similar structured hard-precursors, Nanoscale. 3 (2011) 3052. doi:10.1039/c1nr10334b.

[46] H. Lian, L. Zhang, Z. Meng, Biomimetic hydroxyapatite/gelatin composites for bone tissue regeneration: Fabrication, characterization, and osteogenic differentiation in vitro, Mater. Des. 156 (2018) 381-388. doi:10.1016/j.matdes.2018.07.009.

[47] M.M.M.G.P.G. Mantilaka, H.M.T.G.A. Pitawala, R.M.G. Rajapakse, D.G.G.P. Karunaratne, K.G. Upul Wijayantha, Formation of hollow bone-like morphology of calcium carbonate on surfactant/polymer templates, J. Cryst. Growth. $392 \quad$ (2014) 52-59. doi:10.1016/j.jcrysgro.2014.02.007.

[48] M.M.M.G.P.G. Mantilaka, W.P.S.L. Wijesinghe, H.M.T.G.A. Pitawala, R.M.G. Rajapakse, D.G.G.P. Karunaratne, Surfactant-assisted synthesis of pure calcium carbonate nanoparticles from Sri Lankan dolomite, J. Natl. Sci. Found. Sri Lanka. 42 (2014) 221-228. doi:10.4038/jnsfsr.v42i3.7398.

[49] N.A. Belsey, A.G. Shard, C. Minelli, Surface Chemistry, 2016. doi:10.1002/9781118753460.ch8.

[50] Y.H. Li, S. Wang, X. Zhang, J. Wei, C. Xu, Z. Luan, D. Wu, Adsorption of fluoride from water by aligned carbon nanotubes, Mater. Res. Bull. 38 (2003) 469-476. doi:10.1016/S00255408(02)01063-2.

[51] J.P. Marcolongo, M. Mirenda, Thermodynamics of Sodium Dodecyl Sulfate (SDS) Micellization: An Undergraduate Laboratory Experiment, J. Chem. Educ. 88 (2011) 629-633. doi:10.1021/ed900019u.

[52] E.M. Egorova, S.I. Kaba, The effect of surfactant micellization on the cytotoxicity of silver nanoparticles stabilized with aerosol-OT, Toxicol. Vitr. $57 \quad$ (2019) 244-254. doi:10.1016/j.tiv.2019.03.006.

[53] R. Palepu, Interaction between sodium dodecyl sulfate ( SDS ) and polyvinylpyrrolidone ( PVP ) investigated with forward and reverse component addition protocols employing techniques, (2006) 871-878. doi:10.1007/s00396-005-1453-8.

[54] V.U. Godakanda, H. Li, L. Alquezar, L. Zhao, L.M. Zhu, R. de Silva, K.M.N. de Silva, G.R. Williams, Tunable drug release from blend poly(vinyl pyrrolidone)-ethyl cellulose nanofibers, Int. 
J. Pharm. 562 (2019) 172-179. doi:10.1016/j.ijpharm.2019.03.035.

[55] D.C. Manatunga, R.M. De Silva, K.M.N. De Silva, R. Ratnaweera, Natural polysaccharides leading to super adsorbent hydroxyapatite nanoparticles for the removal of heavy metals and dyes from aqueous solutions, RSC Adv. 6 (2016) 105618-105630. doi:10.1039/c6ra22662k.

[56] K.S.M. Udayakantha, R.M. De Silva, K.M.N. De Silva, C. Hettiarachchi, Biocompatible nano hydroxyapatite - Curcumin bi-coated antibacterial activated carbon for water purification, RSC Adv. 5 (2015) 64696-64703. doi:10.1039/c5ra11518c.

[57] L.H. Hussin, M.H. Yaakob, N. Osman, N.A. Mazlan, EFFECT OF SURFACTANTS ON THE THERMAL DECOMPOSITION OF Li 7 La 3 Zr 2 O 12 CERAMICS, 2 (2013) 49-52.

[58] I.W. Siriwardane, R. Udangawa, R.M. De Silva, A.R. Kumarasinghe, R.G. Acres, A. Hettiarachchi, G.A.J. Amaratunga, K.M.N. De Silva, Synthesis and characterization of nano magnesium oxide impregnated granular activated carbon composite for H2S removal applications, Mater. Des. (2017). doi:10.1016/j.matdes.2017.09.034.

[59] R. Senthil, G. Vijayaragavan, A. Ayeshamariam, K. Kaviyarasu, Nonlinear optical properties of single crystal of L-OOMHCL incorporation with Glycine Oxalic Acid (GOA) with high chemical stability for optoelectronic applications, Surfaces and Interfaces. 18 (2020) 100417. doi:10.1016/j.surfin.2019.100417.

[60] K. Kaviyarasu, A. Mariappan, K. Neyvasagam, A. Ayeshamariam, P. Pandi, R.R. Palanichamy, C. Gopinathan, G.T. Mola, M. Maaza, Photocatalytic performance and antimicrobial activities of HApTiO2 nanocomposite thin films by sol-gel method, Surfaces and Interfaces. 6 (2017) 247-255. doi:10.1016/j.surfin.2016.10.002.

[61] X. Fan, D.J. Parker, M.D. Smith, Adsorption kinetics of fluoride on low cost materials, Water Res. 37 (2003) 4929-4937. doi:10.1016/j.watres.2003.08.014.

[62] N. Chen, Z. Zhang, C. Feng, M. Li, D. Zhu, N. Sugiura, Studies on fluoride adsorption of ironimpregnated granular ceramics from aqueous solution, Mater. Chem. Phys. 125 (2011) 293-298. doi:10.1016/j.matchemphys.2010.09.037.

[63] N.M.I. Alhaji, D. Nathiya, K. Kaviyarasu, M. Meshram, A. Ayeshamariam, A comparative study of structural and photocatalytic mechanism of $\mathrm{AgGaO} 2$ nanocomposites for equilibrium and kinetics evaluation of adsorption parameters, Surfaces and Interfaces. 17 (2019) 100375. 
doi:10.1016/j.surfin.2019.100375.

[64] Y.S. Ho, G. McKay, Pseudo-second order model for sorption processes, Process Biochem. 34 (1999) 451-465. doi:10.1016/S0032-9592(98)00112-5.

[65] S. Gao, R. Sun, Z. Wei, H. Zhao, H. Li, F. Hu, Size-dependent defluoridation properties of synthetic hydroxyapatite, J. Fluor. Chem. 130 (2009) 550-556. doi:10.1016/j.jfluchem.2009.03.007.

[66] Ö.: Neşe, K.T. Ennil, A kinetic study of nitrite adsorption onto sepiolite and powdered activated carbon, Desalination. 223 (2008) 174-179. doi:10.1016/j.desal.2007.01.209.

[67] K. Li, X. Wang, Adsorptive removal of $\mathrm{Pb}(\mathrm{II})$ by activated carbon prepared from Spartina alterniflora: Equilibrium, kinetics and thermodynamics, Bioresour. Technol. 100 (2009) 2810-2815. doi:10.1016/j.biortech.2008.12.032.

[68] G. Atun, T. Sismanoglu, Adsorption of 4,4' - iso propylidene diphenol and diphenylolpropane 4,4' dioxyaceticacid from aqueous solution on kaolinite, J. Environ. Sci. Heal. . Part A Environ. Sci. Eng. Toxicol. 31 (1996) 2055-2069. doi:10.1080/10934529609376474.

[69] B.H. Hameed, M.I. El-Khaiary, Malachite green adsorption by rattan sawdust: Isotherm, kinetic and mechanism modeling, J. Hazard. Mater. 159 (2008) 574-579. doi:10.1016/j.jhazmat.2008.02.054.

[70] I. Tsibranska, E. Hristova, Comparison of different kinetic models for adsorption of heavy metals onto activated carbon from apricot stones, Bulg. Chem. Commun. 43 (2011) 370-377. doi:10.1364/AO.27.003679.

[71] X. Yang, B. Al-Duri, Kinetic modeling of liquid-phase adsorption of reactive dyes on activated carbon, J. Colloid Interface Sci. 287 (2005) 25-34. doi:10.1016/j.jcis.2005.01.093.

[72] V. Sternitzke, R. Kaegi, J.N. Audinot, E. Lewin, J.G. Hering, C.A. Johnson, Uptake of fluoride from aqueous solution on nano-sized hydroxyapatite: Examination of a fluoridated surface layer, Environ. Sci. Technol. 46 (2012) 802-809. doi:10.1021/es202750t.

[73] T. Aoba, The effect of fluoride on apatite structure and growth, Crit. Rev. Oral Biol. Med. 8 (1997) 136-153. doi:10.1177/10454411970080020301.

[74] S. Emin, E. Pavlica, H. Okuyucu, M. Valant, G. Bratina, Charge carrier transport in polycrystalline $\mathrm{CH} 3 \mathrm{NH} 3 \mathrm{PbI} 3$ perovskite thin films in a lateral direction characterized by time-of-flight photoconductivity, Mater. Chem. Phys. $220 \quad$ (2018) 182-189. 
doi:10.1016/j.matchemphys.2018.08.012.

[75] M.S. Fernando, A.K.D.V.K. Wimalasiri, S.P. Ratnayake, J.M.A.R.B. Jayasinghe, G.R. William, D.P. Dissanayake, K.M.N. De Silva, R.M. De Silva, Improved nanocomposite of montmorillonite and hydroxyapatite for defluoridation of water, RSC Adv. 9 (2019). doi:10.1039/c9ra03981c.

[76] J. Wang, W. Xu, L. Chen, Y. Jia, L. Wang, X. Huang, J. Liu, Excellent fluoride removal performance by $\mathrm{CeO} 2-\mathrm{ZrO} 2$ nanocages in water environment, 231 (2013) 198-205. doi:10.1016/j.cej.2013.07.022.

[77] A. Nagaraj, M.A. Munusamy, M. Ahmed, S. Suresh Kumar, M. Rajan, Hydrothermal synthesis of a mineral-substituted hydroxyapatite nanocomposite material for fluoride removal from drinking water, New J. Chem. 42 (2018) 12711-12721. doi:10.1039/c8nj02401d. 